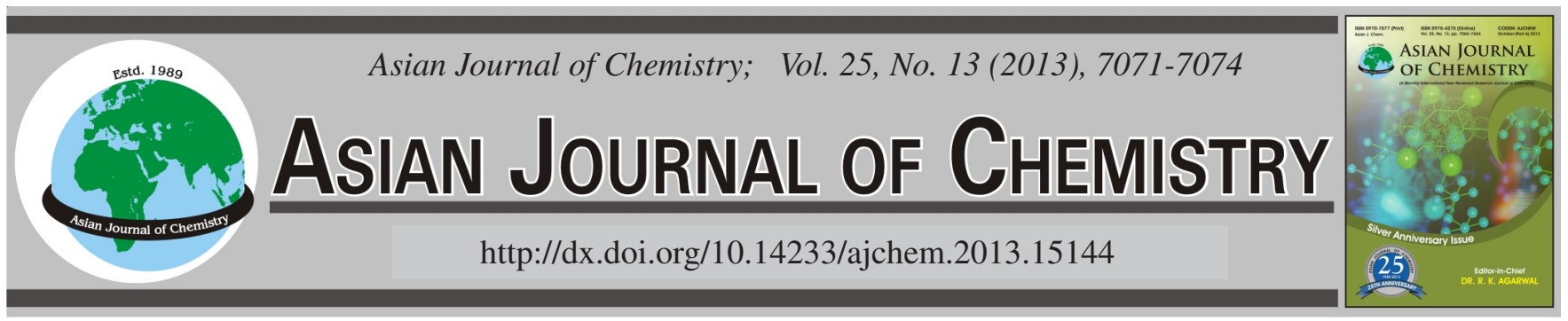

\title{
REVIEW
}

\section{Synthesis and Application of Anionic Polyacrylamide in Water Treatment}

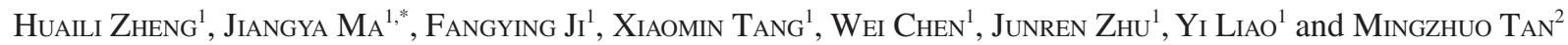

${ }^{1}$ Key Laboratory of the Three Gorges Reservoir Region's Eco-Environment, State Ministry of Education, Chongqing University, Chongqing, 400045, P.R. China

${ }^{2}$ Jiangmen Wealth Water Purifying Agent Co. Ltd., Guangdong 529000, P.R. China

*Corresponding author: Tel: +86 23 65120827; E-mail: majiang_ya@126.com

(Received: 15 January 2013;

Accepted: 12 June 2013)

AJC-13644

\begin{abstract}
This review summarizes the synthesis methods for anionic polyacrylamide. The paper lists six different kinds of anionic polyacrylamide synthesis technologies, including homopolymerization posthydrolysis process, homopolymerization cohydrolysis process, copolymerization approach, inverse emulsion polymerization, precipitation polymerization and radiation polymerization. What's more, the authors discussed the application status of anionic polyacrylamide in water treatment. Based on these reviews, future research perspectives relating to its synthesis and application were proposed.
\end{abstract}

Key Words: Anionic polyacrylamide, Synthesis methods, Water treatment, Flocculants.

\section{INTRODUCTION}

Anionic polyacrylamide (APAM) is a kind of polyacrylamide (PAM) and shows electronegative which contains functional groups of sulfonic acid, phosphoric acid or carboxylic acid $^{1}$. Due to more charge, the molecular chain of polymer can be more stretching in the water which will increase the capacity of adsorption and bridge for suspended particles removal $^{2,3}$. The mainly interaction between APAM and suspended particles is static electricity, hydrogen bonding or covalent bond $^{4-6}$. Anionic polyacrylamide with high molecular weight and good solubility property can be an important kind of flocculants. And it has been widely used in water treatment because of good flocculation performance ${ }^{7}$. Generally, molecular weight of polysaccharide polymer is determined by intrinsic viscosity ${ }^{8}$. Accordingly, how to improve the intrinsic viscosity and solubility property of APAM is the most critical point in the polymerization.

Based on comprehensive literature survey to the preparation technology and application progress of APAM, it can be found that a detailed analysis and review of past academic research progress could be valuable with the rapid development of synthesis technology. Homopolymerization posthydrolysis process, homopolymerization cohydrolysis process, copolymerization approach, inverse emulsion polymerization, precipitation polymerization and radiation polymerization are the main six kinds of synthesis technologies of APAM.
Fundamental aspects of these methods will be introduced and summarized. The developments in applications will also be reviewed and discussed. Finally, the main conclusions and future perspectives are presented.

Synthesis technology progress of APAM: The earliest in 1893, Moureu prepared polyacrylamide by using acryloyl chloride and ammonia in the low temperature. And in 1954, America takes the lead in realizing the industrialization production of polyacrylamide. However, in the 1960s, APAM was firstly developed through alkaline hydrolysis process in the world. Up to now, synthesis technology of APAM has experienced a lot of improvements, the basic reaction of polymerization usually expressed as Fig. 1. According to the APAM synthesis development history of these years, successively appeared the following six different synthesis technologies: Homopolymerization posthydrolysis process, homopolymerization cohydrolysis process, copolymerization approach, inverse emulsion polymerization, precipitation polymerization and radiation polymerization.

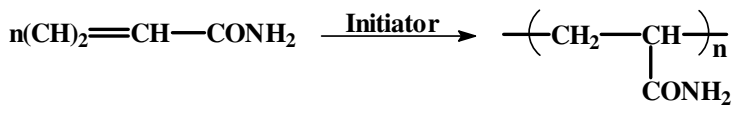

Fig. 1. Basic reaction of acrylamide polymerization

Homopolymerization posthydrolysis process: Fig. 2 presents the technological process of homopolymerization 


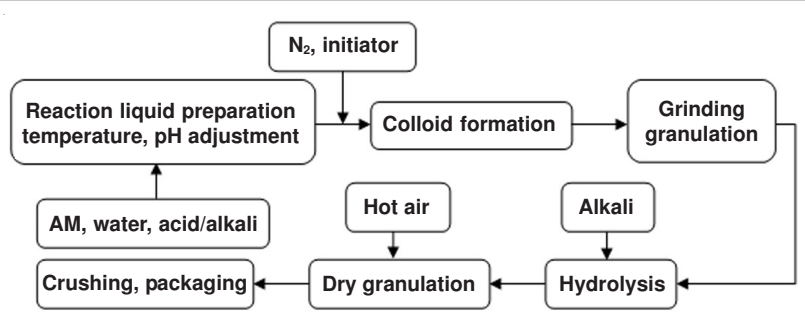

Fig. 2. Technological process of homopolymerization posthydrolysis

posthydrolysis. It is apparent from Fig. 2 that, homopolymerization posthydrolysis process can be divided into two steps. The first one is the basic radical polymerization of acrylamide. Nonionic polyacrylamide is generated in this step. And the second step is completed under the alkaline conditions by adjusting the $\mathrm{pH}$ value more than 7 . In this step, nonionic polyacrylamide hydrolysis will happen. Finally, APAM can be obtained after these two steps.

This technology was widely used in the industrial production. The greatest advantage offered by this process is that the first step of polymerization reaction is conducted in low temperature, which is useful for improving molecular weight of the APAM ${ }^{9}$. However, it also has some disadvantages as follows ${ }^{10}$. Firstly, because of one more step than the other technologies, the polymerization conditions are not easy to control. Secondly, hydrolysis process maybe heterogeneous. It is difficult to reach the control requirements of dissolving properties. What's more, ammonia can be released in the reaction, which will cause not only equipment corrosion, but also environmental pollution, even threaten workers health.

Homopolymerization cohydrolysis process: Based on homopolymerization posthydrolysis process, homopolymerization cohydrolysis process was put forward by simplifying and improving. It can be seen from the Fig. 3 that, sodium is added into the reaction system before polymerization which is the biggest difference with the homopolymerization posthydrolysis process. In this way, the polymerization reaction and hydrolysis will happen at the same time. Hydroxy anion can be produced with the hydrolysis reaction. Finally, we can obtain APAM through drying and granulation.

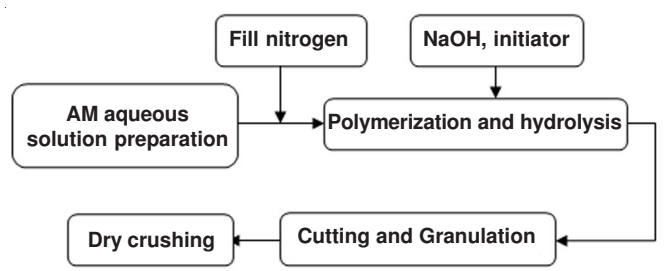

Fig. 3. Technological process of homopolymerization cohydrolysis

Obviously, this method can overcome the common problem of hydrolysis heterogeneous owing to posthydrolysis process $^{11}$. Meanwhile, production device has been simplified to one step. This will greatly reduce the production equipment investment, which can make contribution to lower production $\operatorname{cost}^{12}$.

However, impurities maybe bring in the reaction system resulted from adding sodium before polymerization ${ }^{13}$. These impurities can exist in polymer through polymerization which may affect the properties of the polymer. In addition, tempe- rature of the reaction system will rise at the beginning of adding alkali. On the contrary, the polymerization reaction needs to conduct at low temperature. In this way, it's necessary to cooling down the temperature after adding alkali. Similarly, this technology also cannot solve the problem of equipment corrosion and environmental pollution because of ammonia emissions.

Copolymerization approach: Fig. 4 shows the technological process of copolymerization approach. The core idea of the copolymerization approach is that acrylamide (AM) is polymerized together with other one or two anionic monomers under the initiation. And many small molecule organic matters can be used as anionic monomer, such as sodium acrylate (SAA), 2-acylamido-2-methyl propane sulfonic acid (AMPS), etc. ${ }^{14,15}$. Generally, the polymer of copolymerization can be divided into binary copolymer and terpolymer according to the quantity of different monomer ${ }^{16}$.

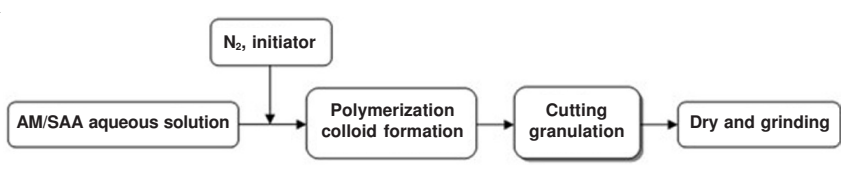

Fig. 4. Technological process of copolymerization

Short production cycle, less process and no ammonia emissions are the advantages of copolymerization approach ${ }^{17,18}$. More important is that degree of hydrolysis can be controlled through copolymerization ${ }^{19}$. Furthermore, excellent quality of APAM can be synthesized with better solubility and higher molecular weight than homopolymerization posthydrolysis and homopolymerization cohydrolysis ${ }^{20,21}$. Based on the above advantages, this technology is widely used in European and American countries.

Nevertheless, there is still a problem that reactivity ratio between acrylamide and other monomers have a big difference (For example: $\mathrm{r}_{\mathrm{AM}}=1.0, \mathrm{r}_{\mathrm{SAA}}=0.35$ ), which can lead to reaction mechanism complicated ${ }^{22,23}$. In this way, it is difficult to optimize synthesis conditions. Moreover, acrylamide with high purity is quite necessary for this approach. Compared to European and American countries, the technology of acrylamide production in China is greatly backward, which is a large obstacle for the application of copolymerization approach in China.

Inverse emulsion polymerization: Under the condition of that monomer water solution as the dispersed phase and water-immiscible organic solvent as continuous phase, inverse emulsion polymerization will be conducted in water-in-oil emulsion $^{24,25}$. Inverse emulsion polymerization is usually used to prepare hydrophilic polymeric particles, such as acrylamide ${ }^{26}$, salt of acrylic acid and $\mathrm{N}$-isopropyl acryl amide ${ }^{27,28}$. The inherent advantage of inverse emulsion polymerization in comparison with the bulk or other polymerization techniques is the fact that this process enables both to reach high molecular weights and high reaction rates during polymerization ${ }^{29}$. What's more, chance of implosion can be greatly reduced owing to the reaction occurs in the oil phase $\mathrm{e}^{30,31}$. Consequently, reaction will be smoothly conducted and the generated heat can be evenly sent out from reaction system. In other words, the reaction is easy to control which can make molecular weight located in a relatively narrow range. 
At the same time, there are also some shortcomings for this technology. The main problem is that it is difficult for emulsification and oil-water separation ${ }^{32,33}$. Moreover, the process of solvent recovery is also very complicated ${ }^{34}$. Up to now, there is still not effective method for solving these problems which is an obstacle for large scale application in the industrial production ${ }^{35}$.

Precipitation polymerization: Precipitation polymerization is a unique method to prepare crosslinked polymer particles in a uniform size and shape in the absence of any added stabilizer ${ }^{36,37}$. In the polymerization mechanism, it was proposed that the particle growth went on through the effective precipitation of nucleated particles due to the non-swell ability of crosslinked primary particles ${ }^{38}$.

For precipitation polymerization, temperature will not be excessive increased with heat dissipation from the reaction system $^{39}$, which is significance for the reaction stability. Furthermore, late in the reaction, the rest of the monomer will not gathered together and can freely diffusion ${ }^{40}$. It's favorable for improving the conversion and molecular weight ${ }^{41}$. The biggest difference with other technology is that most of the residual monomer will stay in solvent, playing a positive effect in preparing APAM with low toxicity and high purity ${ }^{42,43}$. Owing to precipitation in solvent, the polymer can be easy to separation or filter ${ }^{44,45}$. That's all the advantages of precipitation polymerization.

However, development of this technology is not mature enough, failing to realize large-scale industrial production. It's necessary to make efforts on strengthening solvent recovery research for preparing environmental friendly and economical APAM.

Radiation polymerization: Radiation polymerization can be carried out under the high-energy ionizing irradiation, electron beam, $\alpha$-ray, $\beta$-ray, $\gamma$-ray (especially Co-60 $\gamma$ ) and $\mathrm{X}$-ray included ${ }^{46-48}$. The most important mechanism is the generation of ion or free radicals as the active center ${ }^{49-51}$. Fig. 5 shows the mechanism of particle formation during the polymerization of acrylamide initiated under the high-energy ionizing irradiation ${ }^{52,53}$. The reaction can occur at ambient or sub-ambient temperatures and the activation energy is lower than thermal-initiation polymerization ${ }^{54,55}$.

Application in water treatment: After more than a century of development, APAM has been widely used in many fields of every country of the world. Table- 1 shows the application situation of APAM in world major countries. It suggests that APAM is primarily used for water treatment, papermaking, oil exploring and coal washing in mine ${ }^{56}$, especially in water treatment $^{57}$. Obviously, APAM can play an important role in micro-polluted source water, municipal sewage, industrial water treatment, even in excess sludge dewatering ${ }^{58}$.

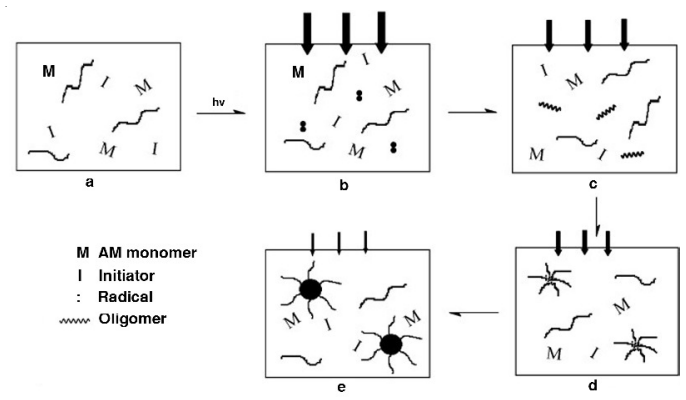

Fig. 5. Mechanism of particle formation during the polymerization of acrylamide initiated by UV light

Generally, due to characteristics of APAM with large specific surface area, linear molecular chain and electrical group is used as absorbent or flocculants in water treatment ${ }^{59}$. Anionic polyacrylamide as a most important coagulant aids has been usually used together with inorganic polymer flocculants such as polyaluminum chloride (PAC) and polymeric ferric sulfate (PFS) in tap water plant and sewage treatment plant for the treatment of micro-polluted source water and municipal sewage respectively ${ }^{60,61}$. Because there are abundant anion groups in the molecular chain, APAM has a great negative potential. Consequently, for the industrial wastewater especially wastewater containing metal, APAM can show a high treatment efficiency through electricity neutralization reaction. However, in sludge dewatering, sludge particles will adsorbed on molecular chain of large specific surface area. Adsorption performance will play an important role in this process and the dewatering efficiency can reach up to $75 \%$.

\section{Conclusion and perspectives}

A critical analysis of literature reveals that much progress has been achieved in applications and research of APAM synthesis technology. However, in recent years, there is a severe trend that composition of wastewater is becoming more and more complicated. Faced with this problem, the traditional flocculent varieties already cannot satisfy the use requirement. Therefore, research and development of composite and special APAM is necessary for the challenge of the new situation.

What's more, as the improvements of the industrial production technical level, APAM will be used in more fields and the usage also will be sharply increased. In this way, characterization of high efficiency, low cost and environmental friendly will become an important development direction of APAM synthesis technology. Specially, improve the conversion rate to reduce the monomer residues should be set as the primary goal. Because monomer acrylamide has nerve toxicity and genetic toxicity to a certain extent which is a potential threat to mankind. Finally, reducing monomer residues is necessary to make contributions to environmental friendly.

TABLE-1

APPLICATION SITUATION OF APAM IN WORLD MAJOR COUNTRIES

\begin{tabular}{ccccccc}
\hline Country & Water treatment & Papermaking & Oil exploitation & Mine & Others & Total $(\%)^{\mathrm{a}}$ \\
\hline America & 60 & 25 & 0 & 11 & 4 & 100 \\
European & 45 & 32 & 12 & 8 & 3 & 100 \\
Japan & 36 & 45 & 35 & 4 & 4 & 100 \\
China & 40 & 15 & 5 & 5 & 100 \\
\hline
\end{tabular}

${ }^{a} \%$ : percentage, unit of each statistical data. 
Above perspectives were proposed to the potential development of APAM synthesis technology in the future. With more efforts being conducted in the research and development, the prospects of developing technologically acceptable and economically feasible synthesis technology over conventional methods are pleasant.

\section{Abbreviation}

APAM : Anionic polyacrylamide

PAM : Polyacrylamide

AM : Acrylamide

SAA : Sodium acrylate

AMPS : 2-Acylamido-2-methyl propane sulfonic acid

PAC : Polyaluminum chloride

PFS : Polymeric ferric sulfate

\section{ACKNOWLEDGEMENTS}

The authors are grateful for the financial support provided by the Cultivation Fund of the Key Scientific and Technical Innovation Project, Ministry of Education of China (NO.708071) and the National Natural Science Foundation of China (Project No. 21177164; 51078366).

\section{REFERENCES}

1. H. Song, S.F. Zhang, X.C. Ma, D.Z. Wang and J.Z. Yang, Carbohydr. Polym., 69, 189 (2007).

2. A. Pourjavadi, S. Barzegar and F. Zeidabadi, React. Funct. Polym., 67, 644 (2007).

3. H.L. Zheng, G.C. Zhu, S.J Jiang and T. Tshukudu, Desalination, 269, 148 (2011).

4. J.P. Zhang, Q. Wang and A.Q. Wang, Carbohydr. Polym., 68, 367 (2007).

5. Y. Bao, J.Z. Ma and N. Li, Carbohydr. Polym., 84, 76 (2011).

6. H.L. Zheng, X.Y. Xiang, M.Z. Tan, G.C. Zhu, Q. He and J.Y. Ma, Asian J. Chem., 25, 1467 (2013).

7. Z. Abdollahi, M. Frounchi and S. Dadbin, J. Ind. Eng. Chem., 17, 580 (2011).

8. Z. Burkus and F. Temelli, Carbohydr. Polym., 54, 51(2003).

9. H.L. Zheng, P. Zhang, G.C. Zhu, Q. He and Z.Q. Zhang, Asian J. Chem., 24, 2598 (2012).

10. H.L. Zheng, Y.X. Pan and X.Y. Xiang, J. Hazard. Mater., 141, 457 (2007).

11. Y.N. Ning, T. Jiang, D.T. Kuang and G.S. Liu, J. Daqing Petrol-China, 24, 37 (2000).

12. D.C. Wan, H.T. Pu and G.J. Yang, Chin. Chem. Lett., 18, 1141 (2007).

13. B. Boutevin, B. Hamoui and J.P. Parisi, Eur. Polym. J., 32, 159 (1996).

14. P. Mehlika and B. Dogan, Mater. Charact., 20, 209 (2001).

15. E.H. Bakraji, N. Salman and I. Othman, Radiat. Phys. Chem., 64, 277 (2002).

16. K. Behari, P.K. Pandey, R. Kumar and K. Taunk, Carbohydr. Polym., 46, 185 (2011).

17. M.A. Talpur, P. Oracz and A. Kaim, Polymer, 37, 4149 (1996).

18. H.F. Ni and D. Hunkeler, Polymer, 38, 667 (1997).

19. C.M. Gibon, S. Norvez, I. Iliopoulos and J.T. Goldbach, Eur. Polym. J., 44, 1843 (2008).

20. M.R. Guilherme, A.V. Reis, S.H. Takahashi, A.F. Rubira, P.A. Feitosa and E.C. Muniz, Carbohydr. Polym., 61, 464 (2005).

21. D.N. Chen, X.G. Liu, Y.M Yue, W.D Zhang and P.X Wang, Eur. Polym. J., 42, 1248 (2006).

22. Y.V. Bune, A.I. Barabanova, Y.S. Bogachev and V.F. Gromov, Eur. Polym. J., 33, 1313 (1997).
23. I. Rintoul and C. Wandrey, Polymer, 46, 4525 (2005).

24. B. Kriwet, E. Walter and T. Kissel, J. Control. Rel., 56, 149 (1998).

25. M. Pabon, J. Selb, F. Candau and R.G. Gilbert, Polymer, 40, 3101 (1999).

26. Z.S. Xu, Y.C. Chen, G.J. Zhang, S.Y. Cheng and L.X. Feng, J. Polym. Sci. Pol. Chem., 37, 2719 (1999).

27. C.L. Lin, W.Y. Chiu and T.M. Don, J. Appl. Polym. Sci., 100, 3987 (2006).

28. Y. Chen, Z. Qian and Z.C. Zhang, Colloid. Surf. A, 312, 209 (2008).

29. D. Benda, J. Sunparek and V. Cermak, Eur. Polym. J., 33, 1345 (1997).

30. D.W. Lim, K.G. Song, K.J. Yoon and S.W. Ko, Eur. Polym. J., 38, 579 (2002).

31. J.P. Yang and B. Weng, Synth. Met., 159, 2249 (2009).

32. L.W. Chen, B.Z. Yang and M.L. Wu, Prog. Org. Coat., 31, 393 (1997).

33. X.Y. Wang, L. Liu, L. Bai, H.F. An, L.P. Zheng and L.H. Yi, J. Noncryst. Solids, 357, 793 (2011).

34. O. Liu, L.S. Wang and S.F. Joseph, Polymer, 52, 63 (2011).

35. P.S. Rao, S. Subrahmanya and D.N. Sathyanarayana, Synth. Met., 128, 311 (2002).

36. C. Bunyakan and D. Hunkeler, Polymer, 40, 6213 (1999).

37. F. Aldabbagh, P.B. Zetterlund and M. Okubo, Eur. Polym. J., 44, 4037 (2008).

38. J.M. Jin, J.M Lee, M.H. Ha, K.S Lee and S. Choe, Polymer, 48, 3107 (2007).

39. R.C. Stringer, S. Gangopadhyay and S.A. Grant, Anal. Chim. Acta, 703, 239 (2011).

40. Y.X. Wang, Q.M. Liu, F. Rong and D.G. Fu, Appl. Surf. Sci., 257, 6704 (2011).

41. S. Chaitidou, O. Kotrotsiou, K. Kotti, O. Kammona, M. Bukhari and C. Kiparissides, Mater. Sci. Eng. B-Solid, 152, 55 (2008).

42. C. Cacho, E. Turiel, E.A. Martin, C.C. Perez and C. Camara, J. Chromatogr. B, 802, 347 (2004).

43. K.C. Ho, W.M. Yeh, T.S. Tung and J.Y. Liao, Anal. Chim. Acta, 542, 90 (2005).

44. Q. Xu, B.X. Han and H.K. Yan, Polymer, 42, 1369 (2001).

45. H. Sambe, K. Hoshina, R. Moaddel and I.W. Wainer, J. Chromatogr. A, 1134, 88 (2006).

46. X.W. Ge, Q. Ye, X.L. Xu and Z.C. Zhang, Polymer, 39, 1917 (1998).

47. O. Guven, M. Sen, E. Karadag and D. Saraydin, Radiat. Phys. Chem., 56, 381 (1999).

48. L.L. Wu, G.X. Wu, S.G. Xu, H. Zhong and Y.J. Shen, J. Environ. Sci. China, 19, 1387 (2007).

49. N.H. Taher, A.M. Dessuoki and M.B. El-Arnaouty, Radiat. Phys. Chem., 53, 437 (1998).

50. A. Acharya, H. Mohan and S. Sabharwal, Radiat. Phys. Chem., 65, 225 (2002)

51. E.L. Madruga, Prog. Polym. Sci., 27, 1879 (2002).

52. K.H. Hong, N. Liu and G. Sun, Eur. Polym. J., 45, 2443 (2009).

53. G. Carabali, E. Chavira, I. Castro and E. Bucio, Radiat. Phys. Chem., 81, 512 (2012).

54. T. Caykara, M. Bulut and S. Demirci, Nucl. Instrum. Meth. B, 265, 366 (2007).

55. X.H. Lv, W.Q. Song, Y.Z. Ti and L.B. Qu, Carbohydr. Polym., 92, 388 (2013).

56. Y.S. Zheng, Shangdong Chem. Ind.-China, 38, 24 (2009).

57. S.F. Zhang and W.J. Zeng, Technol. Prog., 12 (2001).

58. Y. Qi, B. Khagendra, Thapa, F.A. Andrew and Hoadley, Chem. Eng. J., 171, 373 (2011).

59. P. Lanthong, R. Nuisin and S. Kiatkamjornwong, Carbohydr. Polym., 66, 229 (2006).

60. S.A. Seabrook and R.G. Gilbert, Polymer, 48, 4733 (2007).

61. Z.L. Gui, J.W. Qian, Q.F. An, H. Xu and Q. Zhao, Eur. Polym. J., 45, 1403 (2009).

62. T.P. Nguyen, N.P. Hankins and N. Hilal, Desalination, 204, 277 (2007). 